\title{
Modeling of Pedagogical Patterns in an E-learning System
}

https://doi.org/10.3991/ijet.v16i24.26775

\author{
Emil Hadzhikolev, Stanka Hadzhikoleva $\left.{ }^{\bowtie}\right)$, Hristo Hristov, Emil Yonchev, \\ Vladimir Tsvetkov \\ University of Plovdiv "Paisii Hilendarski”, Plovdiv, Bulgaria \\ stankah@uni-plovdiv.bg
}

\begin{abstract}
Pedagogical patterns describe teaching ideas that can be applied in different ways in teaching in different disciplines, and for different types of students. They are a tool for sharing experience and good practices between teachers. The use of pedagogical patterns in online learning is a challenge that can be met by using an appropriate software system for learning management. The article proposes a model of educational objects, suitable for software implementation, which we call pedagogical pattern instances, or for short - instances. One instance combines specific learning content with additional features. Learning content can have different "views" that present knowledge in different ways, for example, through text files of presentations, audio or video content, interactive content, etc. Logical categories of characteristics and activities form the "aspects" of the instance, such as methodology, adaptivity, assessment, etc. The proposed pattern instance model is flexible. It can be expanded with new features and adapted to specific goals and designs. The paper also outlines a conceptual framework of an e-learning software system using the presented model of a pattern instance.
\end{abstract}

Keywords - pedagogical patterns, pedagogical pattern model, pedagogical pattern instances, learning management system

\section{Introduction}

The COVID'19 pandemic conducted a stress test on educational institutions for their readiness to conduct distance learning. Many educational institutions have succeeded because they have already used various software applications for educational resource provision and Learning Management Systems (LMS) to one degree or another. However, the transfer of learning to the digital environment has left a sense of emptiness in learners and teachers. The synchronous e-learning in a digital environment is not commensurate with face-to-face learning. Despite the visual communication carried out through cameras, the teacher cannot communicate freely with the students. The asynchronous e-learning gives more freedom to study at any time and from any place, but takes more time for both teachers and students. The hybrid form of education, which 
combines synchronous with asynchronous learning, emerges as the most successful and preferred [1].

The pandemic has shown that students are ready to use innovative forms of learning [2]. They study with pleasure when there are different forms of gamification in the learning process, and achieve better results in collaborative learning [3], [4]. It is useful and motivating to work in a team on complex tasks close to those solved in a real business environment [5]. Applying knowledge in different areas to solve interdisciplinary tasks inspires learners [6], [7]. They do not like to be bored and look for challenges to demonstrate their abilities to themselves or others. Skills for working in an international environment are also extremely important and easy to train online [8].

Postmodern learning requires the rethinking of already established modern pedagogical practices, theories, methods and methodologies, and adapting them to the rapidly changing needs of students and business organizations. Transferring face-to-face learning to a digital environment does not lead to the same results. The learning process must be reconstructed to offer students intriguing ways to acquire new knowledge and skills without unnecessarily boring them. The transition to postmodern education puts teachers in a new role. Their main tasks are to organize and support the learning process, support the development of students, and be mentors and partners. To do this, they must study, develop and use new educational strategies and techniques for organizing the learning activities, actively using the opportunities of modern ICT.

A new type of learning environment is needed, which on the one hand needs to offer students a variety of forms and models for learning, and on the other hand - to support teachers in the preparation and implementation of a flexible learning process. It must meet the following basic requirements:

- The learning environment should support teaching. Being mentors, evaluators, and colleagues at the same time, in a mode of mixed - synchronous and asynchronous learning, teachers must be ready for different situations. When teaching new knowledge, they must have an arsenal of pedagogical approaches and strategies, sources of knowledge, additional information, and resources to be able to flexibly guide students.

- Encouraging the seeking of knowledge. Assignments should be set to stimulate students to seek solutions to the set tasks by learning "on the go". The constructivist approach to learning should be easy to apply, using appropriate software tools.

- Access to various alternative sources. Students must be able to acquire new knowledge by studying from appropriate sources. The students have different levels of language literacy, technical knowledge, and competencies. Some sources are written in high style and are not understandable by all students. Some students prefer to use video learning resources, while others like to read and discuss what they have learned with colleagues.

- The learning environment should support learning through adaptive learning models. The students are individuals with different interests and competencies. There should be a possibility to adapt the training according to their needs. For example, if the student shows that he has knowledge in some field, e.g., acquired 
through non-formal learning, he must be able to "jump forward" in the learning process. And if there are gaps in their knowledge - to be redirected to appropriate resources for self-learning.

One way to share pedagogical experience and good practice is through the use of pedagogical patterns. Pedagogical patterns capture a recurring problem, the context in which it occurs, and a possible method for solution. They are derived from the experience of pedagogical specialists, supported by methodological and pedagogical practices and theories. Pedagogical patterns are abstract descriptions of real problems and their solutions. They can be used in many different ways, in different subject areas.

Using the concept of pedagogical patterns and trying to transfer them for practical use in a digital environment, we came up with the idea of an instance of a pedagogical pattern. Generally speaking, a pedagogical pattern instance is a complex learning object that packages learning resources for students, with methodological information for teachers and meta-information necessary for its management in LMS.

The article presents a model of a pedagogical pattern instance, which encapsulates the learning content with descriptive information, the purpose of which is to model and manage the learning process in a way that facilitates the teachers, providing them with methodological guidelines, students - through different knowledge outlooks and the ability to adapt the learning process, and allows for automated learning management with the help of LMS.

\section{Pedagogical patterns}

It is believed that the term pattern was first used by the Austrian architect Christopher Alexander. He proposed a new theory of architectural design, which was based on the idea of using the so-called architectural design patterns. According to him - "each pattern describes a problem which occurs over and over again in our environment, and then describes the core of the solution to that problem, in such a way you can use this solution a million times over, without ever doing it the same way twice" [9]. In the book „A Pattern Language: Towns, Buildings, Construction “, Alexander and a team describe 253 architectural patterns. They define recurring problems and solutions for repeated use in architecture. Taken together, the patterns form a new language, which the authors call pattern language [10].

Subsequently, Alexander's ideas about patterns found application in many other areas. The general understanding of the pattern is that a pattern describes an abstract solution of a class of problems and can be used in many different ways in various subject areas. The scientific literature describes patterns for teaching foreign languages, for promoting projects, for presenting new ideas, patterns of business processes, software design patterns, and many more. Patterns are also used in pedagogical science.

The pedagogical patterns describe the experience of experts for various successful practices in the field of teaching and learning. They are a convenient tool for transmitting pedagogical experience, for sharing good practices, and for increasing the competence of young professionals. 
One of the most significant developments in this area belongs to Bergin and team. Their work on the Pedagogical Patterns Project, which aims to promote the identification and dissemination of good practices for learning and teaching object technologies by industry and academia [11]. They create a variety of pedagogical patterns suitable for classroom learning. Following Alexander's ideas, they use the following format to describe the patterns - Problem/Issue, Audience/Context, Forces, Solution, Discussion/Consequences/Implementation, Special resources, Related patterns, Example instances, Contraindications, and References [12]. Later, the results of their work were summarized and published in the book "Pedagogical Patterns: Advice for Educators" [13]. It describes 122 patterns, grouped into 5 categories - "Active Learning", "Feedback", "Experimental Learning", "Gaining Different Perspectives", "Teaching from Different Perspectives".

Iba and Miyake have developed pattern languages, which they call Learning Patterns. Their work on creating Pattern Language for Creative Learning [14] and Pattern Language for Active Learners [15] is significant. Each of the two languages includes about 40 patterns, structured in 3 layers, with different levels of abstraction. For example, in Pattern Language for Creative Learning, at the highest level there is a root pattern - Design Your Learning. It contains information on how and why to use patterns. The second layer has three fundamental patterns - Making Opportunities, Creative Project, and Open-Process Learning. They specify different behaviors that categorize patterns at the third level. The patterns describing different teaching techniques are on the third level. Each pattern is described in a format that consists of the following elements - Pattern name, Introductory Sentences and Illustration, which describe the meaning of the pattern, Quotations rephrase the essence of this pattern with notable sayings, Context is the condition for applying this pattern, Problem describes a difficulty that often occurred in the context but is not easy to overcome, Force is unavoidable laws that make the problem hard to solve, Solution describes the way to solve the problem, and Actions offer concrete approaches to put the solution into practice.

KISTA pattern language is also inspired by Alexander's ideas. It consists of 28 patterns, typed into 6 categories - "Digitalization of teaching material", "Digital Learning Environment", "Open classroom", "Robust classroom technology", "Instruction and documentation technology", and "Student's digital arenas". Here again, the focus is on the didactic and pedagogical aspects of the use of technology in teaching and learning [16].

In [17] a work is presented for creating a design for pedagogy patterns for e-Learning. Scientists adapt Alexander's classic model of design patterns by adding a pedagogical layer. Thus, the emphasis of e-learning design is changing from usability to pedagogy. In other words, they incorporate pedagogy at the core of the design of e-learning. When creating a pedagogical pattern, after defining the problem, the author should research possible solutions, teaching strategies, and optional case studies, which fit constructivist and experimental learning theories, or other pedagogical theories. The structure of the pattern includes the following elements: Name, Background, Problem, Solution, Teaching strategies to accompany this pattern, Consider these other patterns, and Case study. 
Another significant work in the field of pedagogical patterns is presented in the book "Practical Design Patterns for Teaching and Learning with Technology" [18]. The book contains many pedagogical patterns, grouped according to their purpose and application. Each group of patterns is accompanied by design narratives that set the wider context in which the patterns were developed, and by scenarios which project forward to possible novel applications of the patterns, illustrating how they can be adjusted to these new situations. Alexander's design patterns paradigm was developed as a form of design language within architecture. The structure of the patterns includes Summary, Problem, Context, Solution, Support, Related patterns, and Notes. The core of a design pattern can be seen as a local functional statement: "For problem P, under circumstances C, solution $\mathrm{S}$ has been known to work".

Chatteur works on the task of formalizing the relationship between pedagogy and the user interface, information architecture, and content layout of e-learning courseware through design patterns. He creates a design for pedagogy pattern, which shows the relationships between pedagogic strategies associated with the design elements featuring in e-learning courseware and those associated with the general and abstract ways of thinking about education, the preferred teaching practices of the instructors, and the tactics for engaging students [19]. He adapts Alexander's design patterns by adding various pedagogical theories and teaching practices. The structure of the pattern has the following elements: Picture is an optional element that displays the archetypal example of the pattern. Context is an introductory paragraph that explains the applicability of the pattern at a higher level. Problem describes the essence of the problem in 1-2 sentences. Solution is the heart of the pattern - the field of physical and social relationships which are required to solve the stated problem in the stated context. Teaching Strategies outlines pedagogical tactics, that can accompany this design solution. Consider these other patterns contains information about other patterns with which a certain pattern can be combined with. Consider these other solutions is a paragraph outlining the solution in terms of differing pedagogical theories. Case Studies are narrative examples of the solution in practice or short case studies. References is a list of references for further study.

Other pedagogical patterns and pattern languages are described in the literature, which in various ways adapt or expand the structure of Alexander's patterns, for example, for foreign language learning [20], for e-learning [21], and many more. The desire to use pedagogical patterns in e-learning motivates other developments.

Fioravanti and Barbosa consider that pedagogical patterns can be used as a tool to design teaching and learning applications, as well as to improve the existing software applications. They have researched the scientific literature on pedagogical patterns and pedagogical pattern languages. They researched and analyzed 109 pedagogical patterns and created a pedagogical patterns map [22]. The map contains a classification with information about the studied patterns, their application, the problems they solve, etc. It can be used as a guide for pedagogical specialists and designers of LMSs.

May and team have developed a pedagogical design pattern framework for sharing experiences and enhancing communities of practice within online and blended learning [23]. Their framework is characterized by four main elements: Motivations for applying 
a given pattern, Meta-patterns, Pedagogical design patterns, and Macro-patterns. Motivations for applying a given pattern contain information on the reasons why a pattern may be used. This is usually a solution to a set of recurring problems in teaching and learning or a new approach to improving established common practices. Meta-patterns are references to general principles of teaching and learning, for example, "active learning", "problem-based learning", "inquiry-based learning", etc. Their goal is to facilitate teachers by directing them to specific pedagogical theories and models. Pedagogical design patterns are described by the following characteristics - Description (includes a pattern name and a brief description of the idea), Activities (performed by teachers, tutors, and students), Resources (including media and tools), and Use cases (references to the cases where the patterns have been applied or are going to be applied). Macropattern is a combination of patterns that constitute a part of or an entire online or blended learning course.

PatMan is a software application that implements pedagogical patterns through the functionalities available in LMS. The application works as a proxy object for the teacher, helping him establish appropriate configuration settings for the components of the e-learning environment that are needed to implement a particular pattern or a set of patterns [24]. Patterns are instantiated and configured via wizards and hide the technological details for instantiating a pattern from the teacher. They can be viewed and edited during design as well as during operation. The application uses the PCeL pattern repository [25].

\section{Model of a pedagogical pattern instance}

Pedagogical patterns describe an abstract class of tasks or problems and their solutions. To present the same knowledge, different teachers may use different approaches and respectively pedagogical patterns, depending on the experience, vision, students, and sometimes on the current state of the learning environment.

The promotion of patterns and their study is an important prerequisite for their use in the learning process. Our work in creating a catalog of pedagogical patterns and modeling patterns in a software system is presented in [26]. The catalog provides a convenient environment for teachers, where they can get acquainted with abstract problems and their solutions, as well as share experience in their implementation.

The search for ways to effectively use pedagogical patterns in LMS has led us to create the concept of "pedagogical pattern instance", called only "instance" for short. An instance of a pedagogical pattern contains specific knowledge represented by ideas or approaches described in a specific pedagogical pattern. The instance can be used in different ways: for self-learning without the presence of a teacher; face-to-face or online communication in which only the teacher takes advantage of the methodological or didactic instructions in the pattern instance; or hybrid learning, in which the teacher and the student use different parts of the instance.

The need for automated use of the instance in LMS requires the creation of a software model and subsequent implementation. The meaning we put into the concept of a pedagogical pattern instance can be represented by the following definition: 
- Def 1. A pedagogical pattern instance

A pedagogical pattern instance is a complex learning object intended for use in a digital or real environment, for synchronous, asynchronous or blended learning, which encapsulates:

- Learning resources or activities used or performed by students;

- Methodical and pedagogical information to help the teacher;

- Descriptive, formalized information used by the LMS, to form learning pathways. The instance is the main building block for constructing lessons.

- Def 2. A lesson is a multitude of pedagogical pattern instances.

In the general case, the instances in a lesson have a standard arrangement which can be changed depending on the need for modeling adaptivity. Lessons based on pattern instances and adaptivity to them through modeling of learning paths are the subject of further research.

From the student's point of view, the instance presents some knowledge - in different ways and by different means, which they can study. For other types of users, the instance has additional features and related functionalities, which we logically group into aspects.

- Def 3. An aspect of a pedagogical pattern instance is a set of characteristics and related functionalities.

The complete configuration of all aspects and characteristics allows for maximum use of the instance in various forms of education. The minimum required data in one instance are only the training resources and data required by the instance management software system.

The main aspects of the instance are presented in figure 1:

- Identity;

- Methodology;

- Knowledge views;

- Assessment;

- Meta data;

- Management and control;

- Adaptivity;

- User interfaces;

- Other aspects, such as gamification and accessibility. 


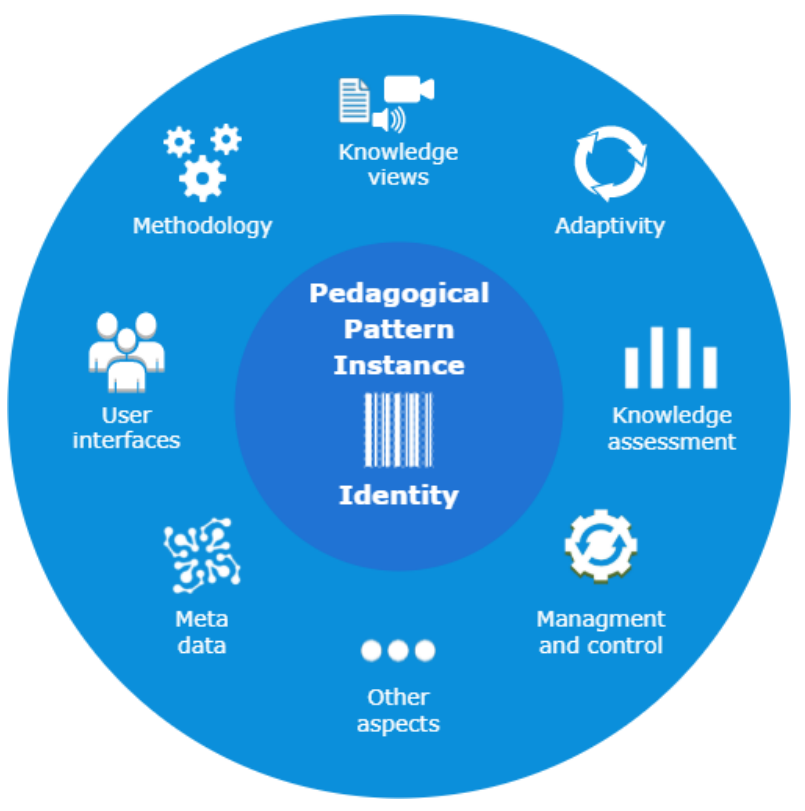

Fig. 1. Pattern instance model

The identity aspect contains characteristics for identifying the instance in the system and classifying it according to different classification schemes:

- Instance identification code through which the instance can be uniquely identified by the instructor or the software system;

- Pattern identifier, which is used conceptually for the construction of the instance;

- Identifiers of the presented knowledge - depending on the needs of the educational organization these may be specific subject area, discipline, textbook, module, lecture, lesson, topic, subtopic, etc.;

- Types of students for which the instance is intended - includes age groups or types of students, e.g., pupils, students, adults, children with SEN, etc.

- Form of education - formal or non-formal education; primary, secondary or higher education; a full-time or part-time form of education;

- Knowledge and skills that students must acquire;

- Other characteristics can be added depending on the specific requirements.

The identifying information can be used when searching for instances according to different criteria by teachers or through automated algorithms. The creation and validation of classification schemes that are used by many different instance creators will facilitate the possibilities of reusability, automated configuration of learning units, and modeling of different types of adaptivity.

Aspect "Methodology" contains a methodical description of the instance intended for the teacher. It explains the practical use of the chosen pattern to represent the knowledge defined for the instance. Depending on whether the instance is intended for 
synchronous, asynchronous, or blended learning, this may include pedagogical guidelines and models, methodological instructions or guidelines for presenting the knowledge of the instance, etc.

Aspect "Knowledge views" contains different types of resources for presenting the same knowledge that can be used by users with different personal preferences. The different views describe the same knowledge but with different technological means and tools. Examples of ways to present knowledge are flat text, audio and video files, multimedia HTML content, which may have embedded formatted text, images, video content, and other types of resources.

Aspect "Assessment" concerns the assessment of the knowledge presented in the instance. It includes one or more questions, test resources, or assignments related only to the knowledge presented in the specific instance. Exam materials can be categorized by complexity, thematic, or other criteria, such as HOTS, LOTS, in order to adapt the learning process to different students, depending on their interests or progress in learning.

Aspect "Meta data" includes information about the author(s) of the instance and the respective organization of the author(s), rights or licenses for the use of the instance, notes by the instance author, and other descriptions.

Aspect "Management and control" is related to the characteristics and activities of the management and control of the instances in the LMS.

Aspect "Adaptivity" provides opportunities to adapt the learning content at the instance level such as automated presentation of a user-friendly view of knowledge according to the personal type; imposing an obligation to conduct an assessment, etc. Determining the student's personality type can help identify his or her learning style [27], [28]. This implies the integration into the system of different tools for classification of personality types according to one or more classification schemes [29], [30], [31], as well as the learner's consent to be the subject of such research.

Aspect "User interfaces" provides interfaces for access of the various roles to certain functionalities of the instance (figure 2). An interface integrates functionalities belonging to one or more aspects. A user with a certain role communicates with the instance only through the respective interface.

The proposed model of a pedagogical pattern instance is complex - it integrates many resources for a flexible learning process. Combining a variety of learning resources and activities for students, together with information to support the work of teachers, and the use of LMS to partially or fully automate and personalize the learning process, can make it more attractive to students, and more rewarding in terms of the results achieved. 


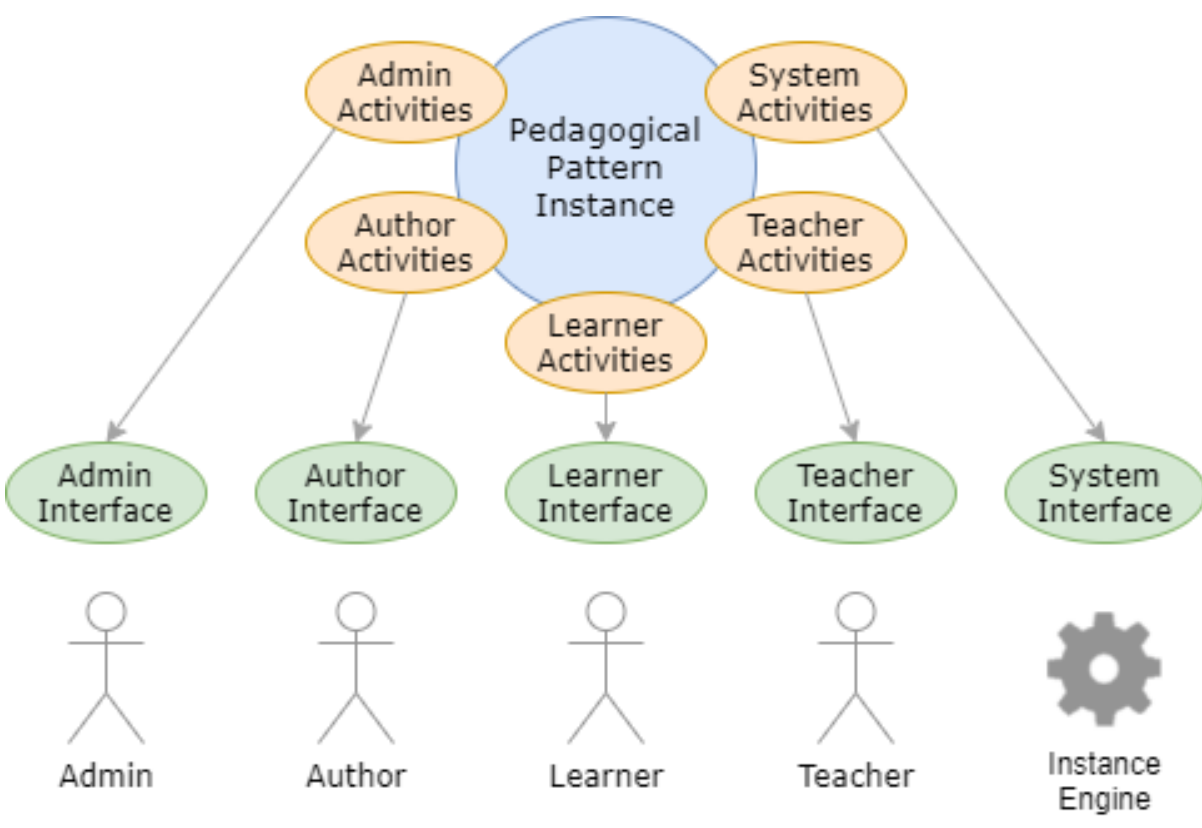

Fig. 2. Interfaces for user access to the activities of pattern instances

\section{Conceptual framework of an educational system based on pedagogical patterns}

Standard roles in an LMS are: an author of learning resources and courses; a teacher who uses the created resources to conduct the education; a student; an administrator with full rights; a moderator of separate courses; a system, carrying out the automated management of the education, etc. The creation of new roles is determined by the choice of a set of objects and activities that can be performed with these objects.

The main roles related to the management of the instances and their main functionalities in the LMS, built on the basis of the presented concept for pedagogical pattern instances (figure 2), are:

- Student - has access only to resources and activities related to his education. The main activities are related to the aspects „Knowledge view” and „Assessment” review of educational resources, participation in discussions, assignments, tests, etc.

- Author of the instance - has access to all functionalities for creating and modifying an instance, including knowledge views, test questions, methodology, etc.;

- Teacher - has access to functionalities related to the implementation of the learning process, including pedagogical strategies, methodological guidelines, guidelines for different types of students, etc.

- LMS - performs activities for management and control of the instances in the system, through a module for management of the pattern instances - Instance Engine. 
This includes the management of adaptive strategies in the instance for the presentation of knowledge and the implementation of test tasks.

- Administrator - has system rights for modeling new interfaces and respectively roles, which in particular reflects on each instance; can perform all user activities on the pattern instance.

The main elements on an LMS based on pedagogical pattern instances are presented in figure 3. In a General Data Storage to store data for LMS users, a catalog of pedagogical patterns; pedagogical pattern instances and lessons, courses and assessments created on them. The catalog of pedagogical patterns can be created as an external system, which is used in LMS when creating instances.

Modeling of instances is performed by authors and teachers with the help of the "Instance Module", which has a graphical user interface for entering the characteristics of all user aspects.

The configuration of lessons as a set of instances is provided by the functionalities of the "Lesson" module. In addition to the basic sequential arrangement of the instances in the lesson, in this module alternative paths between the instances are created, based on roles, conditions, etc. which ensure adaptivity at the level of a lesson.

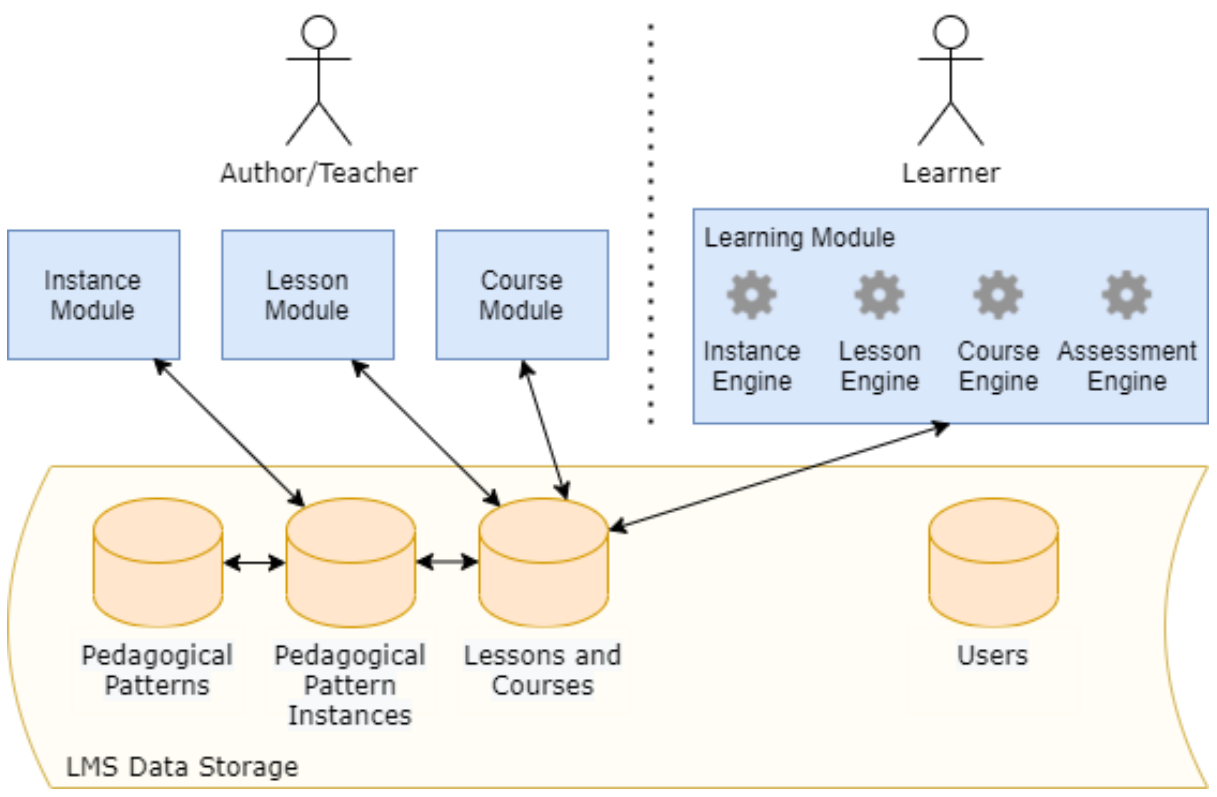

Fig. 3. Main elements in a LMS based on pedagogical patterns

Similarly, in the "Course" module, a number of lessons are configured, forming a complete course. Course-level adaptivity is ensured by modeling alternative pathways between lessons. 
The students' module "Learning" provides functionalities for viewing courses and lessons, as the knowledge of the instances is connected and adapted to the user, depending on assessments, user personality type, user desires, and other conditions. For this purpose, many separate engines take care of the presentation and management of the work with instances, lessons, courses, assessments, etc.

The preparation of an education course involves the following main steps:

1. The author of the instances plans to create a lesson, including knowledge and skills that students need to acquire, learning resources that need to be learned, and activities that need to be performed by students.

2. The author uses the repository of pedagogical patterns to borrow ideas for organizing the lesson through pedagogical patterns.

3. The author creates pedagogical pattern instances that give various opportunities to students to acquire specific knowledge and acquire targeted planned skills.

4. The author of the instances configures a standard learning path, which students must go through in order to successfully complete the planned training.

5. The author of the instances or teacher configures alternative learning pathways through which learning can be adapted for students with different personality profiles.

6. The teacher starts the training by instructing the students on how to organize the training, and if necessary, performs additional activities to determine the personal profiles of the students, for example, by filling out questionnaires.

7. The training is managed with the help of LMS. The specialized training module, taking into account the personal profile of the student, and the specialized information about the pedagogical pattern instances, provides the student with the learning resources adapted for him.

\section{Conclusion}

The quality of education largely depends on the quality of the teachers, the quality of the teaching resources, and methods of teaching. The digital environment offers many temptations that attract attention and it is increasingly difficult to offer attractive training that satisfies students. This sets high and specific requirements for reforming and constructing the learning process in a way that will intrigue students.

The article proposes a conceptual model for teaching in which learning in a digital environment focuses on the use of pedagogical patterns. A conceptual model of a pedagogical pattern instance is described, through which the patterns can be "materialized" and used in the LMS. One pattern instance encapsulates learning resources for students, along with methodological information to assist the teacher and technical information to be used by the LMS to conduct the training. It consists of many aspects that allow for flexible use of learning resources and modeling of learning adaptivity.

The use of an LMS based on pedagogical patterns has many advantages for students and teachers, when conducting synchronous, asynchronous or blended learning, in a digital environment or face-to-face. It minimizes the time required to prepare teachers 
for the teaching process, equipping them with the necessary methodological information. The availability of alternative learning resources and activities in one instance, for the acquisition of specific knowledge and skills, allows for modeling the adaptivity of learning, which undoubtedly makes the learning process more interesting and successful for students.

The proposed conceptual model is open - it can be modified by removing some aspects or adding new ones to meet the specific needs of the educational institution.

\section{Acknowledgment}

The work is funded by the MU21-FMI-004 and MU21-FMI-011 projects at the Research Fund of the University of Plovdiv "Paisii Hilendarski".

\section{$7 \quad$ References}

[1] Mladenova T., Kalmukov, Y., Valova, I. (2020). Covid 19 - A Major Cause of Digital Transformation in Education or Just an Evaluation Test, TEM Journal. Vol. 9, Issue 3, pp. 1163-1170, ISSN 2217-8309. https://doi.org/10.18421/TEM93-42

[2] Kiryakova, G., Angelova, N. (2021). Are the digital learners ready for innovative forms of learning? Mathematics and informatics, Vol. 64, Issue 1, pp. 52-61. https://doi.org/ 10.53656/math2021-1-4-got

[3] Charkova, D., Somova, E., Gachkova, M. (2020). Gamification in cloud-based collaborative learning, Mathematics and informatics, Vol. 63, Issue 5, pp. 471-483.

[4] Zhampeissova, K., Kosareva, I., Borisova, U. (2020). Collaborative Mobile Learning with Smartphones in Higher Education, International Journal of Interactive Mobile Technologies, Vol. 14, No. 21, pp. 4-18. https://doi.org/10.3991/ijim.v14i21.18461

[5] Hristov, H., Krushkov, H. (2016). In-depth interview, Mathematics and informatics, Vol. 59, Issue 4, pp. 368-380.

[6] Tramonti, M., Paneva-Marinova, D. (2019). Maths, Art and Technology: a Combination for an Effective Study, TEM Journal. Vol. 8, Issue 1, pp. 82-86, ISSN 2217-8309.

[7] Xefteris, S., Palaigeorgiou, G. (2019). Mixing Educational Robotics, Tangibles and Mixed Reality Environments for the Interdisciplinary Learning of Geography and History, International Journal of Engineering Pedagogy, Vol. 9, No. 2, pp. 92-88. https://doi.org/10.3991 /ijep.v9i2.9950

[8] Appiah-Kubi, P., Annan, E. (2020). A Review of a Collaborative Online International Learning, International Journal of Engineering Pedagogy, Vol. 10, No. 1, pp. 109-124. https://doi. org/10.3991/ijep.v10i1.11678

[9] Alexander, C. (1979). The Timeless Way of Building. New York: Oxford University Press, ISBN: 0-19-502402-8.

[10] Alexander, C., Ishikawa, S., Silverstein, M., et. al. (1977). A Pattern Language: Towns, Buildings, Construction, Oxford University Press, ISBN-10: 0195019199.

[11] Pedagogical Patterns Project. [Online]. Available: http://www.pedagogicalpatterns.org/. [Accessed Sept. 7, 2021].

[12] Fourteen Pedagogical Patterns. [Online]. Available: http://csis.pace.edu/ bergin/PedPat1. 3.html [Accessed Sept. 7, 2021]. 
[13] Bergin, J., Eckstein, J., Manns, M. et. al. (2012). Pedagogical Patterns: Advice For Educators. CreateSpace Independent Publishing Platform, ISBN: 1479171824.

[14] Iba, T., Sakamoto, M. (2011). Learning Patterns III. A Pattern Language for Creative Learning. Pattern Languages of Programs Conference (PLoP). https://doi.org/10.1145/ 2578903.2579166

[15] Iba, T., Miyake, T., Naruse, M., Yotsumoto, N. (2009). Learning Patterns: A Pattern Language for Active Learners. Pattern Languages of Programs Conference (PLoP). https://doi.org/10.1145/2371736.2371742

[16] Knutsson O., Ramberg R. (2016) Collaborative Pattern Language Representation of Designs for Learning, Designs for Learning Conference, Copenhagen, Denmark.

[17] Chatteur, F., Carvalho, L., Dong, A. (2008). Design for Pedagogy Patterns for E-learning, Eighth IEEE International Conference on Advanced Learning Technologies, https://doi.org/10.1109/ICALT.2008.134

[18] Mor, Y., Mellar, H., Warburton, S., Winters, N. (2014). Practical Design Patterns for Teaching and Learning with Technology, Sense Publishers, ISBN: 978-94-6209-530-4. https://doi.org/10.1007/978-94-6209-530-4

[19] Chatteur, F. (2011). Design for Pedagogy Patterns for E-Learning, PhD Thesys, University of Sydney.

[20] Köppe C., Nijsten M. (2012). A pattern language for teaching in a foreign language: part 1, EuroPLoP '12 Proceedings of the 17th European Conference on Pattern Languages of Programs, Irsee, Germany, ISBN: 978-1-4503-2943-9. https://doi.org/10.1145/2602928. 2603086

[21] Angelova, N., Kiryakova, G. (2018). Sharing good practices and solutions in e-learning through pedagogical patterns, 7th National Conference on e-learning in higher education, Borovets, Bulgaria, pp. 85-93, ISBN 978-954-07-4509-1.

[22] Fioravanti, M., Barbosa, E. (2016). A systematic mapping on pedagogical patterns, 2016 IEEE Frontiers in Education Conference (FIE), ISBN: 978-1-5090-1790-4. https://doi.org/10.1109/FIE.2016.7757407

[23] May, M., Neutszky-Wulff, C., Rosthøj, S., et. al. (2016). A pedagogical design pattern framework, Læring \& Medier (LOM) - nr. 16, pp. 1-24, ISSN: 1903-248X.

[24] Derntl M., Calvo R. (2010). Embedding Educational Design Pattern Frameworks into Learning Management Systems. Technology Enhanced Learning. Quality of Teaching and Educational Reform. Communications in Computer and Information Science, vol 73. Springer, Berlin, Heidelberg. https://doi.org/10.1007/978-3-642-13166-0 62

[25] Derntl M. (2004). The Person-Centered e-Learning Pattern Repository - Design for Reuse and Extensibility. Proceedings of World Conference on Educational Multimedia, Hypermedia, \& Telecommunications (ED-MEDIA'04), Lugano, Switzerland, pp. 3856-3861.

[26] Rachovski, T., Tsvetkov, V., Hadzhikolev, E., Hadzhikoleva, S. (2017). Digital repository of pedagogical patterns, Scientific works of the Russe University, vol. 56, pp. 16-21.

[27] Tahriri, A., Divsar, H., Ashouri, F. (2015). The relationship between EFL learners' personality types and their cognitive learning styles. International Journal of Research Studies in Language Learning, Vol. 4, Number 2, pp. 21-32. https://doi.org/10.5861/ijrsll.2014.843

[28] Afzaal, S., Siau, N., Susanty Hj, W., Suhali (2019). Evaluating Students' Personality and Learning Styles in Higher Education: Pedagogical Considerations, International Journal of Learning, Teaching and Educational Research, Vol. 18, No. 7, pp. 145-164. https://doi.org/ $\underline{10.26803 / \text { ijlter.18.7.10 }}$

[29] McCrae, R., Costa, P. (1987). Validation of the five-factor model of personality across instruments and observers. Journal of Personality and Social Psychology. Vol. 52(1), pp. 8190. https://doi.org/10.1037/0022-3514.52.1.81 
[30] Fleming, N., Mills, C. (1992). VARK - a guide to learning style.

[31] Myers, I., Myers, P. (1995). Gifts Differing: Understanding Personality Type, Publisher: CPP, ISBN-10: 089106074X. '

\section{Authors}

Emil Hadzhikolev is an Associate Professor at the University of Plovdiv "Paisii Hilendarski”, PhD in Computer Science (email: hadjikolev@uni-plovdiv.bg).

Stanka Hadzhikoleva is an Associate Professor at the University of Plovdiv "Paisii Hilendarski", PhD in Computer Science.

Hristo Hristov is an Assistant Professor at the University of Plovdiv "Paisii Hilendarski”, PhD in Pedagogy of Teaching (email: hristo.toshkov@gmail.com).

Emil Yonchev is a PhD student in Computer Science at the University of Plovdiv "Paisii Hilendarski" (email: etj_bg@abv.bg).

Vladimir Tsvetkov is a PhD student in Computer Science at the University of Plovdiv "Paisii Hilendarski” (email: vtsvetkov1005@gmail.com).

Article submitted 2021-09-08. Resubmitted 2021-10-16. Final acceptance 2021-10-16. Final version published as submitted by the authors. 